\title{
Correction to: Review of the Ostichthys japonicus complex (Beryciformes: Holocentridae: Myripristinae) in the northwestern Pacific Ocean, with description of a new species
}

\author{
Mizuki Matsunuma $^{1}$ (D) Yoshino Fukui $^{2} \cdot$ Hiroyuki Motomura $^{3}$
}

Published online: 28 March 2018

(c) The Ichthyological Society of Japan 2018

\section{Correction to: Ichthyological Research \\ https://doi.org/10.1007/s10228-018-0625-8}

The original article was published with an incorrect lowresolution figure 8. It is corrected as given below.
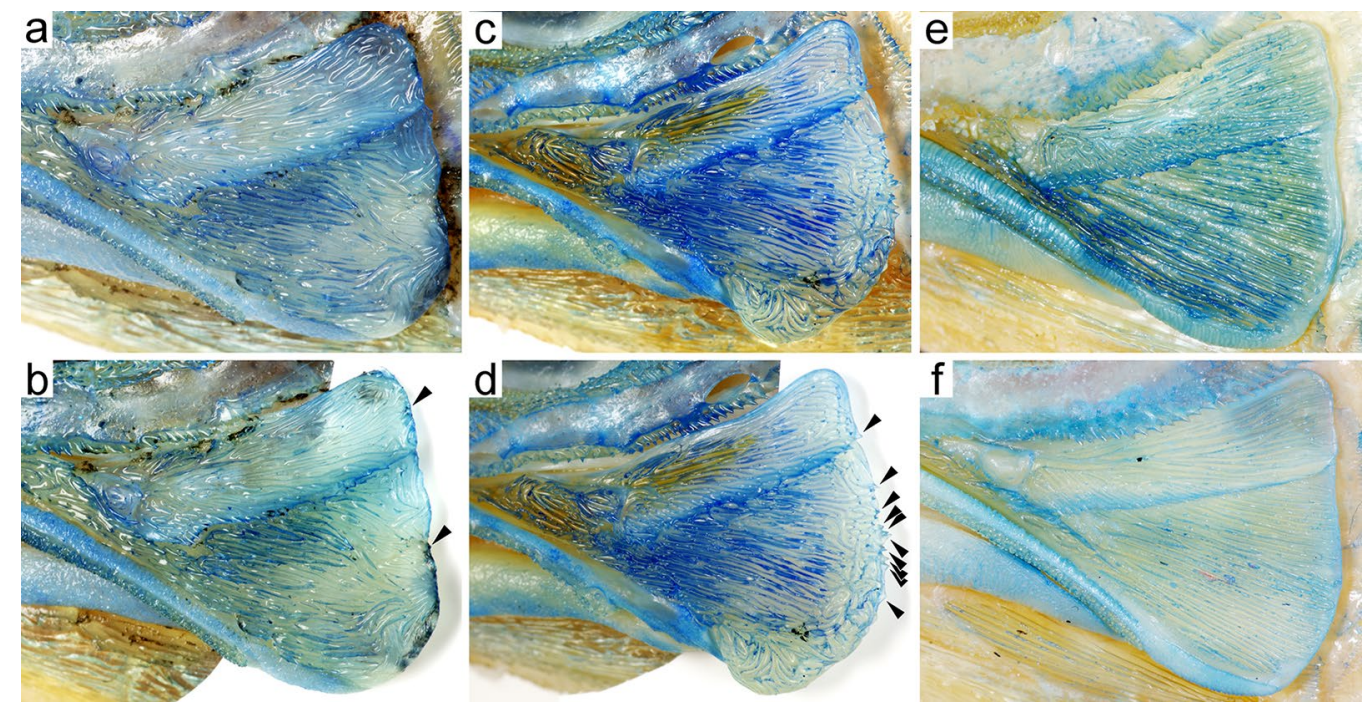

The original article can be found online at https://doi.org/10.1007/ s10228-018-0625-8.

Mizuki Matsunuma

k1139853@kadai.jp

Yoshino Fukui

k5349298@kadai.jp

Hiroyuki Motomura

motomura@kaum.kagoshima-u.ac.jp

1 Laboratory of Marine Biology, Faculty of Science, Kochi University, 2-5-1 Akebono, Kochi 780-8520, Japan

2 The United Graduate School of Agricultural

Sciences, Kagoshima University, 1-21-24 Korimoto,

Kagoshima 890-0065, Japan

3 The Kagoshima University Museum, 1-21-30 Korimoto, Kagoshima 890-0065, Japan 